\title{
Resilience as a mediator of interpersonal relations and depression amongst 10th to 12th grade students
}

\section{Tony Szu-Hsien Lee}

National Taiwan Normal University

\section{Ying-Jhen Wu}

Chung Cheng Armed Forces Preparatory School

\section{En Chao}

National Taiwan Normal University College of Education

\section{Chun-Wei Chang}

Fu Jen Catholic University Hospital

\section{Wang Zhan}

The People's Hospital of Longhua, Shenzhen.

\section{Wen-chi Wu ( $\nabla$ wenchiwu@ntnu.edu.tw )}

National Taiwan Normal University https://orcid.org/0000-0003-4922-6775

\section{Research article}

Keywords: Adolescents, Depression, Interpersonal relations, Mediation, Path analysis, Resilience

Posted Date: September 30th, 2019

DOl: https://doi.org/10.21203/rs.2.15553/v1

License: (1) This work is licensed under a Creative Commons Attribution 4.0 International License. Read Full License 


\section{Abstract}

Background: This study aims to explore the prevalence of depression and examine if resilience is a mediator between interpersonal relationships and depression in senior high school students.

Methods: Of 463 randomly selected participants from 3,900 high school students in a high school, 450 (97.19\%) consented and completed the structured questionnaire which consisted of 4 parts:

Demographics, Inventory of Adolescent Resilience, Taiwan Relationship Inventory for Children and Adolescents, and Center for Epidemiologic Studies Depression Scale for Children.

Results: A total of 94 (20.89\%) had depression, out of which 54 (24\%) were boys and $40(17.78 \%)$ were girls. Results from the path analysis indicated that resilience and interpersonal relationships were negatively associated with students' depression, and interpersonal relations were partially mediated by resilience to depression after controlling for demographics.

Conclusion: Findings support that resilience and better interpersonal relations are protective factors for depression in adolescents. Findings also suggest that better interpersonal relationships can boost resilience to alleviate depression amongst adolescents.

\section{Background}

Adolescents are generally considered a healthy age group; however, approximately $20 \%$ of adolescents undergo a phase of depression before adulthood (World Health Organization, 2012) which is a disease with potentially lethal forms that can result from long-lasting or excessive pressure and can increase the risk of suicide (Haeffel \& Grigorenko, 2007).

The annual incidence of depression at the age of 13 years and 15 years are $1 \% \sim 2 \%$ and $3 \%$ 7\%, respectively, and can increase to as high as approximately $28 \%$ before the age of 19 years (Calles, 2007). A meta-analysis (E. Jane Costello, Alaattin Erkanli, \& Adrian Angold, 2006) reported that the prevalence of depressive disorders in 13- to 18-year-old adolescents was 5.6\%. In Taiwan, the prevalence, comorbidity, and incidence rates of depression among adolescents were no less than those in western countries (Yang, Soong, Kuo, Chang, \& Chen, 2004). A study (Lin et al., 2008) found that $12.3 \%$ of adolescents had experienced depression in a sample of 9,586 adolescents in southern Taiwan. A recent systematic metaanalysis showed that the prevalence of major depressive disorders in Chinese children and adolescents is $1.3 \%$ (Xu et al., 2018).

Studies have documented that a variety of at-risk factors can contribute to depression in children and adolescents, including the death of a loved one, parental divorce, being the victim or witness of domestic violence, changes in residence or school, learning difficulties, academic stress, friendship problems, feelings of neglect or rejection, health conditions, poverty, or a dysfunctional family (Lin et al., 2008; Uusitalo-Malmivaara \& Lehto, 2013; M. B. Yap \& Jorm, 2015; M. B. H. Yap, Pilkington, Ryan, \& Jorm, 2014). Based on the interpersonal model of youth depression (Rudolph, 2008), social-behavioral deficits 
(e.g., ineffective interpersonal problem solving) and poor relationship quality are major factors which heighten the risk for subsequent depression. However, many at-risk children showed good mental health outcomes even when facing many adversities (Werner, 2012).

Some studies have found that positive factors, such as better interpersonal relationships, parental support, and self-competence, ameliorate adolescents from the impact of stressful events or adversity (Braet, Vlierberghe, Vandevivere, Theuwis, \& Bosmans, 2013; C. Y. Wu \& Lee, 2020). For example, a study found evidence for a relationship between resilience and psychological well-being (McDermott, Cobham, Berry, \& Stallman, 2010). Youth with past or current mental illness were more likely to have low scores on a measure of resilience, suggesting that lower levels of resilience are related to increased psychological distress and mental illness through time. Another study (Collishaw et al., 2016) followed 262 families with adolescents and at least one parent diagnosed with a recurrent major depressive disorder. They found that 53 teens, or $20 \%$ of the group, showed sustained good mental health over the four years, with no mental health disorders, no suicidal behavior and better-than-expected mood and behavior. Among high-risk adolescents, resilience factors, including good quality social relationships, warm and supportive parents, a sense of self-efficacy, or regular exercise, were all tied to a higher likelihood of having good mental health. Adolescents are considered resilient with more of these factors when they experience prosocial development despite adversity (Masten, 2013).

Although negative life events and prosocial development factors have been respectively documented to be positively and negatively associated with depression in prior research (Carbonell et al., 2002; M. B. Yap \& Jorm, 2015), empirical evidence is needed to evaluate the role of resilience as a mediator between interpersonal relationships and depression in adolescents. The current study aims to investigate whether better interpersonal relations is a promotional factor for resilience and depression and to determine whether resilience is mediating the interpersonal relationships and depression.

\section{Methods}

\section{Participants and Procedure}

The study protocol was reviewed and approved by the Research Ethics Committee at National Taiwan Normal University (no. 201510HS001). The study purpose and procedure were debriefed to teachers in a high school and then consent forms were distributed to 463 randomly selected students to bring home for parental consent.

A total of 450 (97.19\%) parents gave their consent and their children filled in the structured questionnaire. The questionnaire consisted of 4 parts: Social demographics, Center for Epidemiologic Studies Depression Scale for Children (CES-DC), Inventory of Adolescent Resilience (IAR), and Taiwan Relationship Inventory for Children and Adolescents (TRICA). The questionnaire took about 25 minutes. Each participant was reimbursed with 100 New Taiwan dollars (approximately 3.30 US dollars) for their participation. 


\section{Measures}

Demographics include gender, grade, family income, paternal education, and maternal education. The students' grade level was recorded as $10^{\text {th }}, 11^{\text {th }}$, or $12^{\text {th }}$ grade. Family income was defined by New Taiwan dollars (NTD) into 4 categories: less than or equal to $\$ 20,000$ NTD, $\$ 20,001$ NTD to $\$ 50,000$ NTD, $\$ 50,001$ NTD to $\$ 80,000$ NTD, and equal to or more than $\$ 80,001$ NTD. Parental education was coded as less than junior high, high school, and college and above.

The Center for Epidemiological Studies Depression Scale for Children (CES-DC) is a 20-item self-reported depression inventory (Radloff, 1977). Items include assessments of the past week, and ratings vary between 0 (none of the time) to 3 (most or all of the time) on four-point Likert-type questions, of which four items have been scored in reverse. The total score ranges from 0 to 60 , and a higher score indicates a higher level of depression. Reliability and validity for the adolescents were proved to be significant in previous Asian studies (Chin, Choi, Chan, \& Wong, 2015; Heo, Choi, Yu, \& Nam, 2018; Wang et al., 2013; Yang et al., 2004). The cut-off point for depression is 23 for boys and 26 for girls, based on a study conducted on 2440 students aged 12 to 16 years in Taipei, Taiwan (Yang et al., 2004), although different cut-off scores are reported in different languages and different cultures.

The Taiwan Relationship Inventory for Children and Adolescents (TRICA) was developed with 1,018 high school students in Taiwan (H. C. Wu, Wu, Hsu, \& Shiau, 2008) and consists of three dimensions: parentchild relations, teacher-student relations, and peer relations. Parent-child, teacher-student, and peer relations have 24,14 , and 14 items, respectively, which sums to a total of 52 items. Results from a confirmatory factor analysis had adequate item loadings. Cronbach's a and the test-retest reliability coefficient over a two-week interval for the three dimensions range from.77 to.86, and.73 to.88, respectively. Each item was responded to and coded as never (1), seldom (2), sometimes (3), or always (4). A higher score represents better relations.

Resilience was measured by the Inventory of Adolescent Resilience (IAR) which is researched and validated based on items proposed in literature (Chan, Yeh, Peng, \& Yeh, 2009). Results from the confirmatory factor analysis identified four factors: problem-solving and cognitive maturity (10 items), hope and optimism (6 items), empathy and interpersonal interaction (9 items), and emotional adjustment (3 items), and the variances extracted were $19.64 \%, 17.82 \%, 14.42 \%$, and $8.96 \%$ respectively, with $60.90 \%$ of variances explained in total. Each item was responded to and coded with never (1), seldom (2), sometimes (3), or often (4). A higher score indicates better resilience. Cronbach's a for IAR was.936.

\section{Statistical analysis}

All of the analyses were performed using SPSS, version 23 (SPSS Inc., Chicago) and Mplus version 5.0. To estimate the prevalence of depression, each participant was categorized into groups labelled as either depressed or non-depressed based on the cut-off scores of 23 for boys and 26 for girls, respectively. Furthermore, we use path analysis to investigate the mediation role of resilience between interpersonal 
relationships and depression. Two mediation models, without and with demographics, were analyzed using resilience as a mediator. All alpha levels were set at $p<0.05$.

\section{Results}

Half of the respondents are boys; participants are equally recruited from $10^{\text {th }}, 11^{\text {th }}$, and $12^{\text {th }}$ graders; $55.1 \%$ self-reported that their family income was between $\$ 20,001$ NTD and $\$ 50,000$ NTD per month; $25.3 \%$ had a monthly income of $\$ 50,001$ NTD to $\$ 80,000$ NTD, and $13.6 \%$ received less than $\$ 20,000$ NTD per month. With respect to paternal education level, $58.2 \%$ reported that their father had high school degree; $24.5 \%$ had junior high or less, and $17.3 \%$ had a college education. Out of those who reported their mother's education level, $63.6 \%$ reported that their mother had completed high school; $19.1 \%$ had a college education, and $17.3 \%$ had completed junior high or less.

With respect to CES-DC, 94 (20.89\%), 54 (24\%) of boys and 40 (17.78\%) of girls scored higher than the corresponding cut-off points and thus were categorized as having depression. Table 1 presents the results from the logistic regression of demographics, interpersonal relationships, and resilience to examine factors associated with depression. Results showed that none of the demographic variables were significantly associated with depression, but resilience and interpersonal relationships were significantly associated with participants' depression. Specifically, the odds ratios of depression by resilience and interpersonal relationships were.87 and.95, respectively.

Figure 1 and Figure 2 present the results of two mediation models of resilience between depression, interpersonal relationships, and demographics. In Figure 1, social demographics were not included in the model, and results show that resilience and interpersonal relationships were negatively associated with depression. After accounting for the effect of resilience $(\beta=-.444, p<.01)$, the direct effect between interpersonal relationships and depression remained significant $(\beta=-.423, p<.01)$, indicating partial mediation. To clarify whether the sequence of interpersonal relationships and resilience can be reversed, the mediation model of interpersonal relationships between resilience and depression was examined, and the fit statistics did not meet the acceptable criteria (results not shown; available on request).

In Figure 2, social demographics were included in the path analysis, and results showed that resilience is a full mediator between demographics and depression because none of the demographics had a significant direct effect on depression. The standardized coefficients remained at the same level in Figure 1 between interpersonal relationships, resilience, and depression.

\section{Discussion}

There are several important findings in this study. First, the prevalence rate of depression in this study is about $20.89 \%$, which is higher than the findings of previous studies (E. Jane Costello, A. Erkanli, \& A. Angold, 2006; Lin et al., 2008). One possible explanation for the rates of depression varying from study to study may be due to the assessment tools and criterion used in different studies. For example, a study 
conducted in mainland China used a rigorous criteria found that the rate of major depressive disorders in adolescents is $1.3 \%$ (Xu et al., 2018). Another explanation is that academic stress is high for high school students in our study due to the pressure of having to perform well on university entrance exams and pressure from parents (Chiang et al., 2013). Chinese students were found to avoid blame from parents and negative feelings by spending more time studying and doing homework, rooted in Confucian teachings of placing value on one's efforts (Fwu, Wang, Chen, \& Wei, 2016). Moreover, researchers have found that Chinese adolescents who perceived high academic pressure were more likely to experience depressive symptoms (Zhang, Li, Gong, \& Ungar, 2013). Although the higher rate of depression in our study sample should be interpreted cautiously, its prevalence still demonstrates the importance and urgency of examining the factors that protect adolescents from depression.

Second, the finding that gender, parental education, and family income are not associated with depression is not consistent with some of previous studies (Biggs, Nelson, \& Sampilo, 2010; Victor, Hipwell, Stepp, \& Scott, 2019; Wirback, Moller, Larsson, Galanti, \& Engstrom, 2014), although mixed results are found in the literature. For example, a study (Somchit \& Sriyaporn, 2004) demonstrated that girls were more resilient than boys in a sample of 267 children aged 9 to 16, whereas other research showed no significant differences in gender nor grade regarding resilience in adolescents (Hjemdal, Vogel, Solem, Hagen, \& Stiles, 2011; Wichstrom, 1999). On the other hand, through their research on family income in 12 cities from 1991 to 2010, a study (Bhana \& Bachoo, 2011) found that higher- and middle-income families are more resilient than lower-income families, and that good support systems have a strong influence on the promotion of resilience in families. Additionally, researchers found that in order to promote resilience in children, mothers with higher education pay more attention to their children's growth and actively participate in their education and emotional management (Ellingsen, Baker, Blacher, \& Crnic, 2014).

Third, interpersonal relationships and resilience are significantly associated with depression. The finding on interpersonal relationships and depression is consistent with previous studies (Biggs et al., 2010; La Greca \& Harrison, 2005; Uusitalo-Malmivaara \& Lehto, 2013). For instance, La Greca and Harrison (2005) found that multiple levels of 421 adolescents' interpersonal functioning predict symptoms of depression. In addition, Hjemdal and his colleagues (2010) focused on 307 high school students in Norway and indicated that students with a higher level of resilience had a lower level of depression.

Fourth, our finding shows that resilience partially mediates the association between interpersonal relationships and depression. To our knowledge, this is the first study which investigates the mediation role of resilience between interpersonal relationships and depression in Chinese adolescents. Resilience and interpersonal relationships work as collaborators who have a cumulative effect on reducing depression. The results also imply that students with poor interpersonal relationships can be protected from depression by having greater resilience, because resilience has a negative association with depression. Rutter (1987) substantiated that psychological resilience protects people against adversities via four processes: reducing risk impact, reducing negative chain reactions, establishing self-esteem and 
self-efficacy, and creating opportunities. This study provides empirical evidence which supports the protective effect of resilience in facing adversity and lowers the risk impact.

Fifth, resilience is a full mediator between social demographics and depression. The direct associations between demographics and depression were diminished after accounting for the mediation effect of resilience. Adolescents living with well-educated and wealthy parents usually have sound support systems. The support systems such as family, schools, friends, and communities can help adolescents build resilience by providing positive and harmonious family relationships, care from peers, and affection or substantial benefits from adults (Herrman et al., 2011; Hurd \& Zimmerman, 2010). Therefore, with the support of others as the coping capacity, individuals can transform adolescence into a significant developmental period (Cicchetti \& Rogosch, 2002; Zolkoski \& Bullock, 2012). Studies have confirmed that support systems can help individuals interact more actively with others to increase trust in others, reduce loneliness, improve self-confidence, and see things positively (Carbonell et al., 2002; Wright \& Masten, 2005). Resilience helps cope with stress, and adolescents with a higher level of resilience show less depressive temperament and are more likely to protect themselves against depression (Gundogar, Kesebir, Demirkan, \& Yaylaci, 2014). Although adolescence is a risky period for depression, resilient adolescents will be able to overcome adversity and respond positively, as well as increase opportunities for successful adaptation and growth. (Haddadi \& Besharat, 2010).

\section{Study Limitations}

There are some limitations in this study. The high school students in this study were recruited from a single high school, although they were randomly sampled. The representativeness is limited. The measures in this study were self-reported, which may be biased by social desirability. Another limitation is that no family factors were included in this study. Despite the limitations, the measures used in this study are reliable and valid. Like any cross-sectional designs, the study does not allow for confident causal inference.

\section{Conclusions}

This study identified that one in five of the participants have depression, and the students with strong interpersonal relationships have a lower level of depression than their counterparts. It is noteworthy that strong interpersonal relationships increase resilience, which in turn decreases depression. Furthermore, resilience acts as a partial mediator between interpersonal relationships and depression, and a full mediator between demographic characteristics and depression. Future research should investigate the mediation effect of resilience between interpersonal relationships and depression with a longitudinal design to clarify the causal relationships among them. Based on the results, providing training for students to increase their interpersonal interaction skills, and increasing the support and opportunities for building resilience, might be an effective way to reduce the development of depression among adolescents. 


\section{References}

Bhana, A., \& Bachoo, S. (2011). The determinants of family resilience among families in low- and middleincome contexts: A systematic literature review. South African Journal of Psychology, 41(2), 131-139.

Biggs, B. K., Nelson, J. M., \& Sampilo, M. L. (2010). Peer relations in the anxiety-depression link: test of a mediation model. Anxiety Stress Coping, 23(4), 431-447. doi:10.1080/10615800903406543

Braet, C., Vlierberghe, L. V., Vandevivere, E., Theuwis, L., \& Bosmans, G. (2013). Depression in Early, Middle and Late Adolescence: Differential Evidence for the Cognitive Diathesis-Stress Model. Clinical Psychology \& Psychotherapy, 20(5), 369-383. doi:10.1002/cpp.1789

Calles, J. L., Jr. (2007). Depression in children and adolescents. Prim Care, 34(2), 243-258; abstract vi. doi:10.1016/j.pop.2007.04.008

Carbonell, D. M., Reinherz, H. Z., Giaconia, R. M., Stashwick, C. K., Paradis, A.D., \& Beardslee, W. R. (2002). Adolescent Protective Factors Promoting Resilience in Young Adults at Risk for Depression. Child and Adolescent Social Work Journal, 19(5), 393-412. doi:10.1023/a:1020274531345

Chan, Y. C., Yeh, Y. C., Peng, Y. Y., \& Yeh, B. L. (2009). The Development of the Inventory of Adolescent Resilience. Psychological Testing, 56(4), 491-518.

Chiang, Y. C., Lee, T. S. H., Yen, L. L., Wu, C. C., Lin, D.C., Hurng, B. S., \& Chang, H. Y. (2013). Influence of stressors and possible pathways of onset of seventh graders' suicidal ideation in urban and rural areas in Taiwan. BMC Public Health, 13, 1233. doi:10.1186/1471-2458-13-1233

Chin, W. Y., Choi, E. P., Chan, K. T., \& Wong, C. K. (2015). The Psychometric Properties of the Center for Epidemiologic Studies Depression Scale in Chinese Primary Care Patients: Factor Structure, Construct Validity, Reliability, Sensitivity and Responsiveness. PLoS One, 10(8), e0135131.

doi:10.1371/journal.pone.0135131

Cicchetti, D., \& Rogosch, F. A. (2002). A developmental psychopathology perspective on adolescence. $J$ Consult Clin Psychol, 70(1), 6-20. doi:10.1037//0022-006x.70.1.6

Collishaw, S., Hammerton, G., Mahedy, L., Sellers, R., Owen, M. J., Craddock, N.,... Thapar, A. (2016).

Mental health resilience in the adolescent offspring of parents with depression: a prospective longitudinal study. Lancet Psychiatry, 3(1), 49-57. doi:10.1016/s2215-0366(15)00358-2

Ellingsen, R., Baker, B. L., Blacher, J., \& Crnic, K. (2014). Resilient parenting of children at developmental risk across middle childhood. Research in developmental disabilities, 35(6), 1364-1374. doi:10.1016/j.ridd.2014.03.016

Fwu, B.-j., Wang, H. H., Chen, S.-W., \& Wei, C.-F. (2016). 'Feeling bad' or 'being bad?' The trapping effect of effort in academic failure in a Confucian cultural context. Educational Psychology, 37, 1-14. 
Gundogar, D., Kesebir, S., Demirkan, A. K., \& Yaylaci, E. T. (2014). Is the relationship between affective temperament and resilience different in depression cases with and without childhood trauma? Compr Psychiatry, 55(4), 870-875. doi:10.1016/j.comppsych.2014.01.016

Haddadi, P., \& Besharat, M. A. (2010). Resilience, vulnerability and mental health. Procedia - Social and Behavioral Sciences, 5, 639-642. doi:https://doi.org/10.1016/j.sbspro.2010.07.157

Haeffel, G. J., \& Grigorenko, E. L. (2007). Cognitive vulnerability to depression: exploring risk and resilience. Child Adolesc Psychiatr Clin N Am, 16(2), 435-448, x. doi:10.1016/j.chc.2006.11.005

Heo, E. H., Choi, K. S., Yu, J. C., \& Nam, J. A. (2018). Validation of the Center for Epidemiological Studies Depression Scale among Korean Adolescents. Psychiatry Investig, 15(2), 124-132. doi:10.30773/pi.2017.07.19

Herrman, H., Stewart, D. E., Diaz-Granados, N., Berger, E. L., Jackson, B., \& Yuen, T. (2011). What is resilience? Can J Psychiatry, 56(5), 258-265. doi:10.1177/070674371105600504

Hjemdal, O., Vogel, P. A., Solem, S., Hagen, K., \& Stiles, T. C. (2011). The relationship between resilience and levels of anxiety, depression, and obsessive-compulsive symptoms in adolescents. Clin Psychol Psychother, 18(4), 314-321. doi:10.1002/cpp.719

Hurd, N., \& Zimmerman, M. (2010). Natural mentors, mental health, and risk behaviors: a longitudinal analysis of African American adolescents transitioning into adulthood. American journal of community psychology, 46(1-2), 36-48. doi:10.1007/s10464-010-9325-x

Jane Costello, E., Erkanli, A., \& Angold, A. (2006). Is there an epidemic of child or adolescent depression? Journal of Child Psychology and Psychiatry, 47(12), 1263-1271. doi:10.1111/j.1469-7610.2006.01682.x Jane Costello, E., Erkanli, A., \& Angold, A. (2006). Is there an epidemic of child or adolescent depression? J Child Psychol Psychiatry, 47(12), 1263-1271. doi:10.1111/j.1469-7610.2006.01682.x

La Greca, A.M., \& Harrison, H. M. (2005). Adolescent peer relations, friendships, and romantic relationships: do they predict social anxiety and depression? J Clin Child Adolesc Psychol, 34(1), 49-61. doi:10.1207/s15374424jccp3401_5

Lin, H. C., Tang, T. C., Yen, J. Y., Ko, C. H., Huang, C. F., Liu, S. C., \& Yen, C. F. (2008). Depression and its association with self-esteem, family, peer and school factors in a population of 9586 adolescents in southern Taiwan. Psychiatry Clin Neurosci, 62(4), 412-420. doi:10.1111/j.1440-1819.2008.01820.x

Masten, A. S. (2013). Resilience. Retrieved from http://www.childencyclopedia.com/resilience/introduction 
McDermott, B. M., Cobham, V. E., Berry, H., \& Stallman, H. M. (2010). Vulnerability factors for disasterinduced child post-traumatic stress disorder: the case for low family resilience and previous mental illness. Aust N Z J Psychiatry, 44(4), 384-389. doi:10.3109/00048670903489916

Radloff, L. S. (1977). The CES-D Scale:A Self-Report Depression Scale for Research in the General Population. Applied Psychological Measurement, 1(3), 385-401. doi:10.1177/014662167700100306

Rudolph, K. D. (2008). Developmental influences on interpersonal stress generation in depressed youth. Journal of abnormal psychology, 117(3), 673-679. doi:10.1037/0021-843X.117.3.673

Somchit, S., \& Sriyaporn, P. (2004). The relationships among resilience factors, perception of adversities, negative behavior, and academic achievement of 4th- to 6th-grade children in thad-thong, chonburi, thailand. Journal of Pediatric Nursing: Nursing Care of Children and Families, 19(4), 294-303. doi:10.1016/j.pedn.2004.02.004

Uusitalo-Malmivaara, L., \& Lehto, J. E. (2013). Social Factors Explaining Children's Subjective Happiness and Depressive Symptoms. Social Indicators Research, 111(2), 603-615. doi:10.1007/s11205-0120022-z

Victor, S. E., Hipwell, A. E., Stepp, S. D., \& Scott, L. N. (2019). Parent and peer relationships as longitudinal predictors of adolescent non-suicidal self-injury onset. Child Adolesc Psychiatry Ment Health, 13, 1. doi:10.1186/s13034-018-0261-0

Wang, M., Armour, C., Wu, Y., Ren, F., Zhu, X., \& Yao, S. (2013). Factor structure of the CES-D and measurement invariance across gender in Mainland Chinese adolescents. J Clin Psychol, 69(9), 966979. doi:10.1002/jclp. 21978

Werner, E. E. (2012). Children and war: risk, resilience, and recovery. Dev Psychopathol, 24(2), 553-558. doi:10.1017/s0954579412000156

Wichstrom, L. (1999). The emergence of gender difference in depressed mood during adolescence: the role of intensified gender socialization. Dev Psychol, 35(1), 232-245.

Wirback, T., Moller, J., Larsson, J. O., Galanti, M. R., \& Engstrom, K. (2014). Social factors in childhood and risk of depressive symptoms among adolescents-a longitudinal study in Stockholm, Sweden. Int J Equity Health, 13, 96. doi:10.1186/s12939-014-0096-0

World Health Organization. (2012). Adolescent mental health. Retrieved from Geneva, Switzerland:

Wright, M. O. D., \& Masten, A. S. (2005). Resilience Processes in Development: Fostering Positive Adaptation in the Context of Adversity. In Handbook of resilience in children. (pp. 17-37). New York, NY, US: Kluwer Academic/Plenum Publishers. 
Wu, C. Y., \& Lee, T. S.-H. (2020). Impact of parent-child relationship and sex on trajectories of children internalizing symptoms. Journal of affective disorders, 260, 167-173.

doi:https://doi.org/10.1016/j.jad.2019.09.016

Wu, H. C., Wu, Y. C., Hsu, W. Y., \& Shiau, R. J. (2008). Development of the Taiwan Relationship Inventory for Children and Adolescents (TRICA) and its Psychometric Study. Psychological Testing. Psychological Testing, 55(3), 535-557.

Xu, D. D., Rao, W. W., Cao, X. L., Wen, S. Y., Che, W. I., Ng, C. H.,... Xiang, Y. T. (2018). Prevalence of major depressive disorder in children and adolescents in China: A systematic review and meta-analysis. $J$ Affect Disord, 241, 592-598. doi:10.1016/j.jad.2018.07.083

Yang, H. J., Soong, W. T., Kuo, P. H., Chang, H. L., \& Chen, W. J. (2004). Using the CES-D in a two-phase survey for depressive disorders among nonreferred adolescents in Taipei: a stratum-specific likelihood ratio analysis. J Affect Disord, 82(3), 419-430. doi:10.1016/j.jad.2004.04.008

Yap, M. B., \& Jorm, A. F. (2015). Parental factors associated with childhood anxiety, depression, and internalizing problems: a systematic review and meta-analysis. J Affect Disord, 175, 424-440. doi:10.1016/j.jad.2015.01.050

Yap, M. B. H., Pilkington, P. D., Ryan, S. M., \& Jorm, A. F. (2014). Parental factors associated with depression and anxiety in young people: A systematic review and meta-analysis. Journal of affective disorders, 156, 8-23.

Zhang, W., Li, H., Gong, Y., \& Ungar, M. (2013). Stressful events and depression among Chinese adolescents: The mitigating role of protective factors. School Psychology International, 34(5), 501-513. doi:10.1177/0143034312472760

Zolkoski, S. M., \& Bullock, L. M. (2012). Resilience in children and youth: A review. Children and Youth Services Review, 34(12), 2295-2303. doi:10.1016/j.childyouth.2012.08.009

\section{Tables}

Table 1. Depression of high school students predicted by demographic variables using logistic regression 


\begin{tabular}{|c|c|c|c|}
\hline Variables & Odds Ratio & \multicolumn{2}{|c|}{ 95\% Confidence Interval for OR. } \\
\hline \multicolumn{4}{|l|}{ Gender } \\
\hline Female (RC) & 1.00 & & \\
\hline Male & 0.77 & .41 & 1.43 \\
\hline \multicolumn{4}{|l|}{ Grade } \\
\hline 1 year (RC) & 1.00 & & \\
\hline 2 year & 1.05 & .51 & 2.16 \\
\hline 3 year & 1.20 & .58 & 2.51 \\
\hline \multicolumn{4}{|l|}{ Family Income } \\
\hline$<20,000(\mathrm{RC})$ & 1.00 & & \\
\hline $20,000-49,999$ & .88 & .38 & 2.00 \\
\hline $50,000-79,999$ & .43 & .15 & 1.20 \\
\hline$>=80,000$ & 1.55 & .43 & 5.29 \\
\hline \multicolumn{4}{|l|}{ Paternal Education } \\
\hline$<=9$ years $(\mathrm{RC})$ & 1.00 & & \\
\hline $10-12$ years & 1.23 & .58 & 2.60 \\
\hline$>12$ years & .75 & .20 & 2.80 \\
\hline \multicolumn{4}{|l|}{ Maternal Education } \\
\hline$<=9$ years $(\mathrm{RC})$ & 1.00 & & \\
\hline $10-12$ years & 1.14 & .50 & 2.57 \\
\hline$>12$ years & .89 & .25 & 3.15 \\
\hline \multirow{2}{*}{\multicolumn{4}{|c|}{ Resilience }} \\
\hline & & & \\
\hline Relationship & $.95^{* * *}$ & .93 & .97 \\
\hline
\end{tabular}

Note. RC口Reference Category.

Figures 


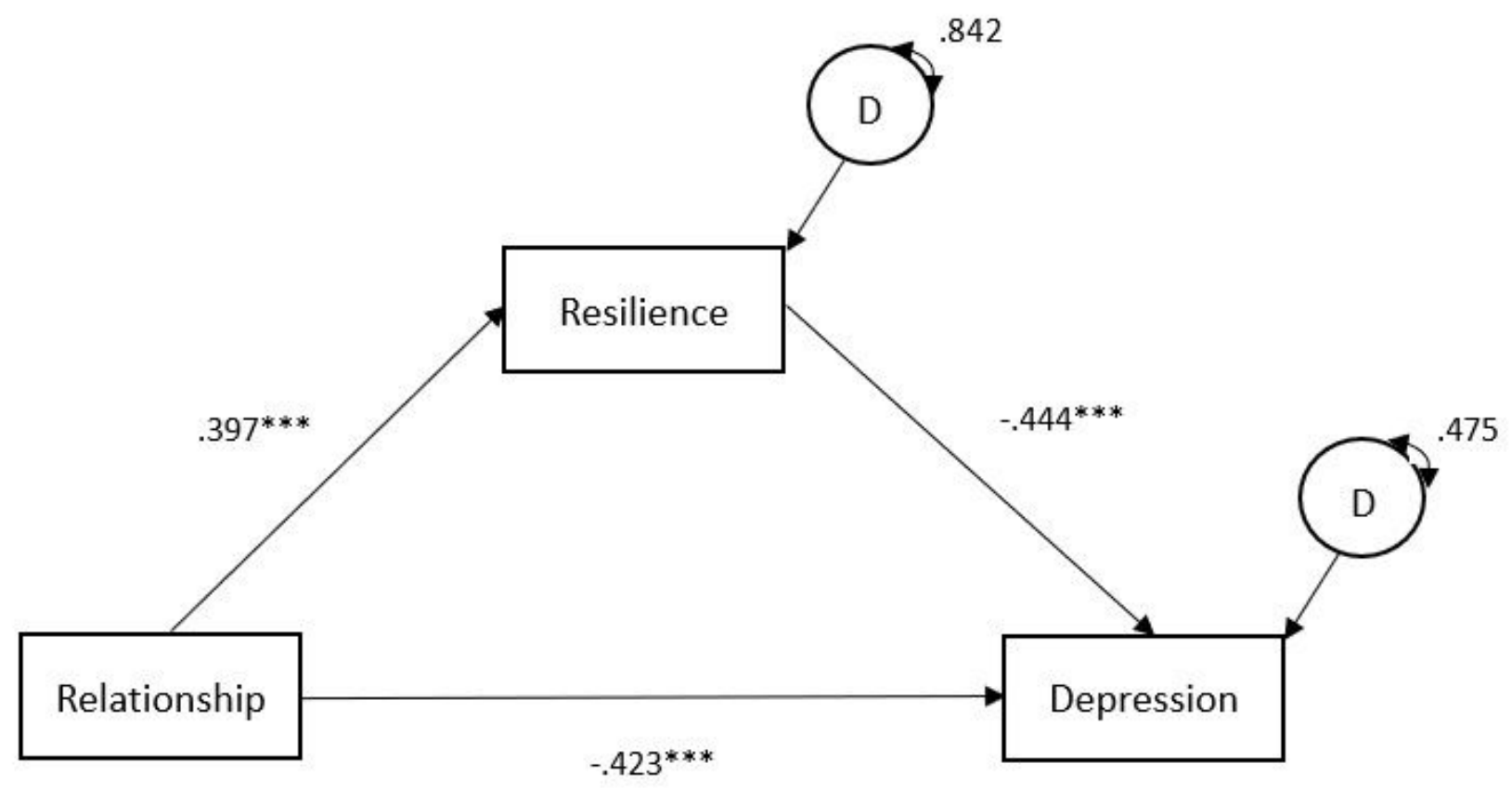

\section{Figure 1}

Direct and indirect pathways between interpersonal relationship, resilience, and depression. Standardized path coefficients; model adjusted R2 $=.525$ 


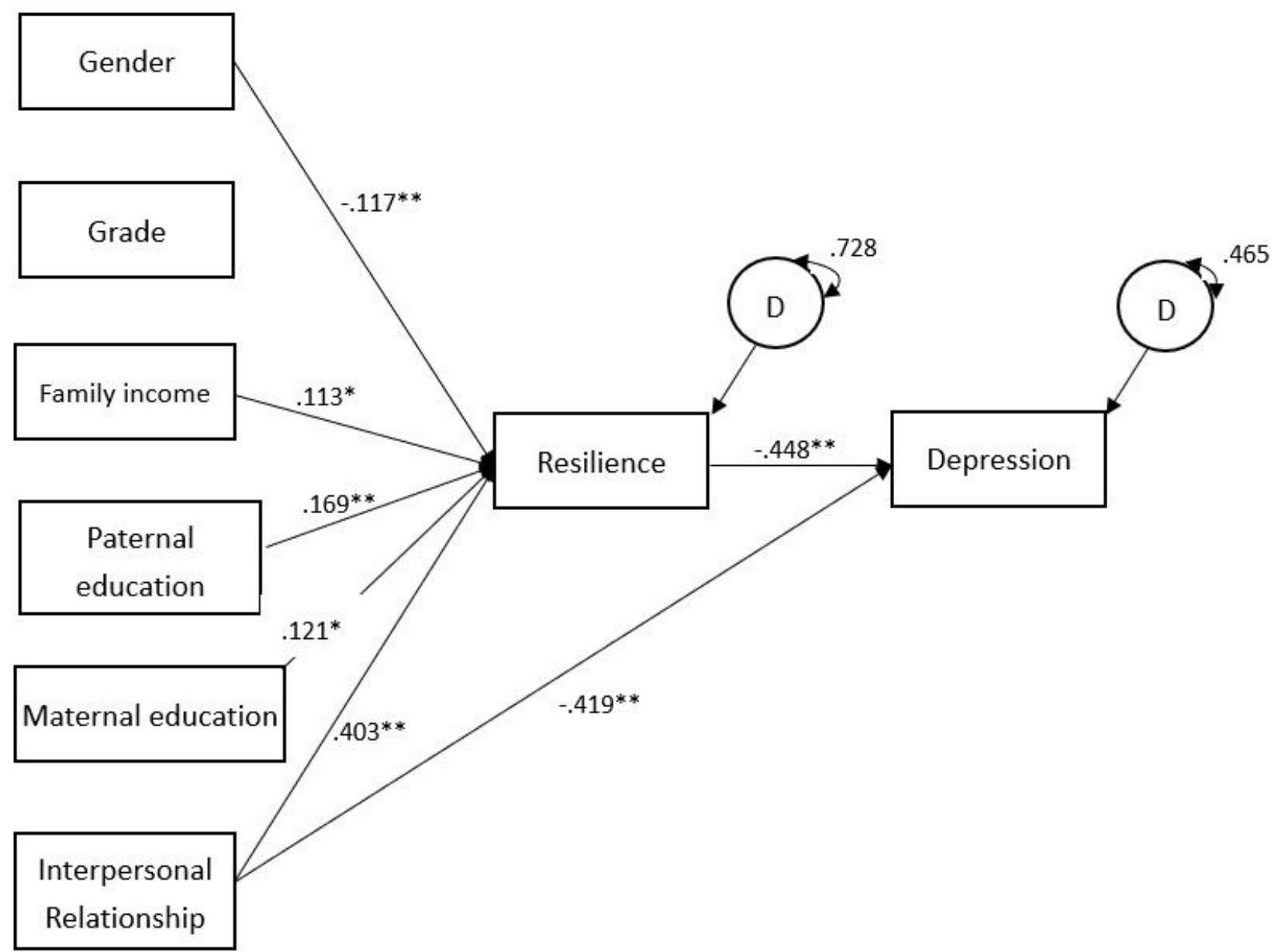

Figure 2

Direct and indirect pathways between demographics, interpersonal relationship, resilience, and depression. Standardized path coefficients; model adjusted R2 $=.535$ 